\title{
O DISCURSO DO MARKETING DE LUGAR E OS GRANDES EVENTOS
}

\author{
Michel Nicolau Netto*
}

\begin{abstract}
Os grandes eventos se globalizam na mesma medida em que proliferam os lugares promovidos como marcas. Embora autônomos, esses processos estão relacionados ao se fundarem numa visão de que os lugares devem competir na globalização e que a competição deve se dar a partir de suas imagens. Esse tipo de competição se embasa num discurso produzido por publicitários de marketing de lugar, que tanto manuseiam formas simbólicas construídas como identidades coletivas, quanto se engajam na produção de novos elementos, de forma a configurá-los, tal qual as marcas de produtos, como diferencial competitivo. Neste artigo, investigo a atuação desses publicitários, compreendidos como artífices de um "senso comum planetário" que ressignifica a imagem do lugar a partir de concepção de uma marca. Serão aqui analisados os pressupostos desse discurso, suas instâncias de legitimidade e sua relação com os grandes eventos, que devem ser entendidos como espaços de consagração e circulação do discurso do marketing de lugar.

PaLAVRAS-Chave: Globalização. Identidade. Marketing. Branding. Megaeventos.
\end{abstract}

\section{INTRODUÇÃO1}

Os grandes eventos se globalizam na mesma medida em que vemos a proliferação de lugares promovidos como marcas ou, em uma terminologia do marketing, como brands. Embora autônomos, esses processos estão relacionados ao se fundarem numa visão de que os lugares devem competir na globalização e que a competição deve se dar a partir de suas imagens. Tais imagens seriam capazes de garantir aos lugares a atração de um capital móvel e de formas variadas de prestígio global, o que se materializaria na própria recepção de grandes eventos. Por sua vez, esses eventos seriam plataformas globais que, uma vez sediadas em um lugar, promoveriam a imagem desse lugar para o globo. Esse processo circular de justificativa de dois fenômenos cria a percepção de

\footnotetext{
* Universidade Estadual de Campinas (Unicamp). Instituto de Filosofia e Ciências Humanas (IFCH). Departamento Sociologia.

Rua: Cora Coralina, 100 - Cidade Universitária, Campinas - SP, 13083-896. Telefone: 19 35211914.mnicolau@unicamp.br

${ }^{1}$ Este artigo só foi possível pelos apoios concedidos, recentemente, pela FAPESP e pelo programa FAEPEX da Unicamp.
}

que a produção simbólica do lugar nos termos promovidos nos grandes eventos é "natural". Perde-se de vista, assim, que essa forma de produção simbólica se embasa num discurso produzido por artífices interessados em sua própria produção. Refiro-me aos publicitários do marketing de lugar, cujas práticas são centrais para a compreensão da formação de um "senso comum planetário", que reduz a imagem do lugar à concepção de branding.

Este artigo investiga as práticas desses agentes no intuito de desnaturalizar a produção que propõem e demonstrar que a relação entre grandes eventos e promoção do lugar, em verdade, consagra e torna global um tipo de discurso sobre o lugar embasado numa suposta homologia entre mercado e mundo. Para tanto, no primeiro item, serão analisados o processo de globalização dos grandes eventos e a posição dos publicitários do marketing de lugar no campo de produção desses eventos. No segundo item, buscarei demonstrar as bases do discurso desses publicitários e as instâncias envolvidas em sua legitimidade. No último item, relacionarei a generalização do discurso dos publicitários com os grandes eventos. 


\section{A GLOBALIZAÇÃO DOS GRANDES EVENTOS}

Em 2007, foram sediados, na cidade do Rio de Janeiro, os Jogos Pan-americanos, marcando o início de uma série de grandes eventos internacionais no Brasil. Em 2011, ocorreram os Jogos Mundiais Militares; em 2012, o Rio + 20; em 2013, a Jornada Mundial da Juventude e a Copa das Confederações de Futebol; em 2014, a Copa do Mundo de Futebol; em 2015, os Jogos Mundiais dos Povos Indígenas; e, em 2016, os Jogos Olímpicos e os Jogos Paraolímpicos. A esses se somam os grandes eventos de música que ocorrem em vários lugares do mundo, mas que também pousam no Brasil, em datas que já marcam um calendário: Rock in Rio, cuja primeira edição se deu no Brasil em 1985, e, mais tarde, foi sediado em Lisboa, Madrid e Las Vegas, e, desde 2011, ocorre anual ou bienalmente no Rio de Janeiro; Lolapallooza, que ocorre desde 1991 em Chicago, desde 2011 em Santiago, desde 2014 em Buenos Aires, desde 2015 em Berlim, faz seu debut em 2016 em Bogotá e, desde 2012, anualmente, ocorre em São Paulo. Os shows internacionais no Brasil também proliferaram nos últimos anos e se, em 2010, foram 234 shows de artistas estrangeiros realizados no país, em 2015, foram 1.116 shows. ${ }^{2}$ Se pegarmos apenas aqueles considerados pela bibliografia especializada como exemplares do que se chamou de "megaeventos"3 (ver, por exemplo, Roche, 2000) - Jogos Olímpicos (Verão e Inverno), Copa do Mundo de Futebol e Expo Mundial -, + apenas o último não veio ao Brasil nesta últii. ¿ 1722435 -numero-de-shows-internacionais ค่

$\doteq{ }^{3}$ Não utilizarei aqui o termo megaevento, mas sim grandes î eventos. O termo faz parte hoje do arsenal das ciências sociais, mas requer um tratamento mais qualificado para $\nexists$ poder ser tratado como categoria, algo já criticado por ouస్ tros autores (MacAloon, 2006). Como não me disporei a isso aqui, pois não haverá espaço, adoto o termo genérico, I propositalmente impreciso, mas que não me induz ao erro

ک comum de confundir termos descritivos com categorias sociológicas. Para meus fins aqui, basta ter em mente alguma ideia de magnitude e a noção de que são eventos globalmente móveis, pois ocorrem em diferentes lugares pelo mundo. ma década. Mas não por falta de esforço: São Paulo foi derrotado por Dubai em seu pleito para sediar o evento em 2020.

O cenário brasileiro, contudo, não é excepcional. Para onde olhamos, encontramos antigos e novos grandes eventos. Eles estão em lugares onde antes não estavam, onde costumavam estar e onde talvez não imaginávamos que estariam. Somando Olimpíadas (Verão e Inverno), Copa do Mundo de Futebol e Expo Mundial, notamos que 26 países já sediaram ao menos uma de suas 107 edições somadas, entre 1851 (ano da considerada primeira Expo Mundial, em Londres) e 2022 (ano da já programada Copa do Mundo de Futebol no Qatar, e dos Jogos Olímpicos de Inverno, em Pequim). Os oito países que mais sediaram esses eventos o fizeram em 67 oportunidades, ou seja, 62,6\% das edições, sendo eles: EUA (com 16), França (com 13), Alemanha, Itália e Bélgica (com 7 cada), Japão e Inglaterra (com 6 cada) e Espanha (com 5). Se, contudo, contarmos apenas a partir de 2001, dos 21 eventos realizados ou previstos, esses mesmos oito países sediaram ou sediarão sete eventos, ou seja, 33\%. Entre os países que mais sediarão esses eventos há novidades: China (que nunca havia sediado um desses eventos, e sediará, até 2022, uma Expo Mundial e duas Olimpíadas - Verão e Inverno), Emirados Árabes (que sediará a Expo Mundial em 2020), Qatar (que sediará a Copa do Mundo de Futebol de 2022), África do Sul (que sediou uma Copa do Mundo de Futebol em 2010), além de Brasil, Rússia e Coréia do Sul. que já haviam sediado esses eventos antes e reaparecem.

Se há uma clara relação contemporânea entre os chamados países emergentes (especialmente os conhecidos como BRICs) e as sedes de grandes eventos (Horne, 2014), não se pode, contudo, pensar em uma transferência do interesse dos países centrais da modernidade para esses. O que há, na verdade, é uma globalização, que se nota pelo fato de que os antigos países continuam sediando esses eventos, ou, ao menos, interessados em sediá-los. É preciso lembrar que, entre 2001 e 2022, a Inglaterra 
terá sediado uma edição das Olimpíadas de Verão (Londres, 2012), os EUA uma das Olimpíadas de Inverno (Salt Lake City 2002), a Alemanha uma Copa do Mundo de Futebol (2006), a Itália uma Olimpíada de Inverno (Turim 2006) e uma Expo Mundial (Milão 2015) e o Japão uma Copa do Mundo de Futebol (2002) e uma Olimpíada de Verão (Tóquio 2020). Ainda vale lembrar que várias foram as tentativas frustradas desse grupo de países em sediar outros eventos desde 2001, como a Inglaterra, que se candidatou para a Copa do Mundo de 2018, ou os Estados Unidos, que ofereceram Chicago para sediar as Olimpíadas de Verão de 2014. Ainda para as Olimpíadas de Verão de 2024, Paris, Roma e Los Angeles já foram anunciadas como candidatas, ao lado de Budapeste. A globalização desses eventos também se observa pelo fato de que países que não se encontram entre aqueles considerados emergentes ou centrais também participam desse circuito. O Azerbaijão, cuja capital Baku foi postulante sem sucesso a sediar os Jogos Olímpicos de 2016 (concorrendo com Rio de Janeiro, Madri, Tóquio, Chicago, Doha e Praga) e de 2020 (concorrendo com Tóquio, Istambul, Madrid, Doha e Roma), obteve êxito em seu pleito para sediar os I Jogos Europeus, em 2015. ${ }^{4}$

A globalização, ao mesmo tempo em que une a todos, a todos diferencia em sua totalidade. A geografia dos grandes eventos segue essa dinâmica e, se expandirmos o olhar para as sedes de outros grandes eventos, como Expos Internacionais, campeonatos mundiais de outros esportes, etc., veremos outros países entrarem na lista acima. Os Jogos do Commonwealth, que ocorrem a cada quatro anos desde 1930, apenas na sua XVI edição, em 1998, teve como sede um país asiático, a Malásia. Em 2010, os jogos foram para a Índia e, para 2022, está prevista a primeira edição no continente africano, na África do Sul. A instituição que, desde 1934, comanda as Expos Mundiais, o Bureau Internacional des Expositions (BIE), organiza-

\footnotetext{
${ }^{4}$ Agradeço Luã Ferreira Leal pela lembrança.
}

rá uma Expo Internacional ${ }^{5}$ em Antalya, Turquia, em 2016, e outra em Astana, no Cazaquistão, em 2017. Somente em 2015 e 2016, a FIFA chancelou campeonatos mundiais de futebol em nove países, conforme a Tabela 1.

Tabela 1 - Torneios de futebol organizados pela FIFA e suas sedes

\begin{tabular}{l|l|l}
\hline Torneios masculinos & \multicolumn{1}{|c}{ País-sede } & Tipo de evento \\
\hline 2015 & Nova Zelândia & Sub 20 \\
2015 & Chile & Sub 17 \\
2015 & Japão & Mundial de clubes \\
2015 & Portugal & Futebol de areia \\
2016 & Colômbia & Futsal \\
2016 & Brasil & Torneio Olímpico \\
\hline Torneios femininos & \multicolumn{1}{|c}{ País-sede } & Tipo de evento \\
\hline 2015 & Canadá & Copa do Mundo \\
2016 & Papua Nova Guiné & Sub 20 \\
2016 & Jordânia & Sub 17 \\
2016 & Brasil & Torneio Olímpico \\
\hline
\end{tabular}

nte: Fifa Disponível em: www.fifa.com. Acesso em: 25/01/2016

Se somarmos a esses outros grandes eventos internacionais, como grandes feiras de negócios e grandes congressos das diversas áreas, veremos que o mundo está interligado nesse circuito, ${ }^{6}$ embora de forma assimétrica. Formam-se, de fato, processos e instituições nacionais e globais especializados nisso, reverberando o processo dinâmico e dual pelo qual Saskia Sassen descreveu a globalização. Para ela, a globalização é produzida por "instituições e processos tipicamente globais", que, no caso aqui analisado, são as empresas que administram e produzem os eventos, ${ }^{7}$ as ${ }^{5}$ Uma espécie de Expo Mundial reduzida e especializada em certo tema. Interessante notar que o BIE hierarquiza suas exposições e relaciona a dimensão global a essa hierarquia. Ver: http://www.bie-paris.org/site/en.

${ }^{6}$ A associação internacional de congressos e convenções afirma que, nos últimos 10 anos, dobrou a quantidade de eventos internacionais, sendo que, em 2014, a associação contabilizou 11.505 eventos que possuíam as seguintes características: ocorrer regularmente, ter, ao menos, 50 participantes e ser rotativo por, pelo menos, três países. Esses eventos ocorreram em 111 países. Ver o relatório ICCA Statistics Report 2014, retirado de http://www.iccaworld. com/npps/presscentre.cfm. Acesso em: 25/01/2016.

${ }^{7}$ Por exemplo, a Reed Exhibitions. Empresa com sede na Inglaterra e escritórios em 41 países, a Reed organiza mais de 500 eventos em 36 países da Ásia, da África, da Europa, da Oceania e da América. No Brasil, a Reed se uniu à Alcântara Machado, empresa também organizadora de eventos estabelecida no país em 1956, formando a Reed 
multinacionais que detêm a marca e o direito de exploração comercial dos eventos (como FIFA e $\mathrm{COI}^{8}$ ), as empreiteiras e as empresas de arquitetura que desenham e constroem as estruturas necessárias ${ }^{9}$ (Damo; Oliven, 2014, p. 119-136), as consultorias que prestam assessoria às candidaturas das cidades e países a sede dos eventos, etc. Algumas dessas instituições foram criadas em um período anterior, muitas delas surgiram recentemente; todas, contudo, têm um modo de operação global.

Mas a globalização também envolve processos e instâncias que "ocorrem profundamente dentro dos territórios e domínios institucionais que foram construídos amplamente em termos nacionais na maior parte do mundo [...]" (Sassen, 2007, p. 6), mas que hoje operam a partir de uma agenda global. É o caso do surgimento, dentro das estruturas estatais, de secretarias, comitês, comissões, câmeras temáticas, que se dedicam aos grandes eventos. É também o caso de órgãos nacionais voltados para a atração desses eventos (como os Con-

Exhibitions Alcântara Machado. Essa empresa é responsável pela organização de grandes eventos internacionais, como Salão do Automóvel, Bienal do Livro e World Travel Market Latin America, todos em São Paulo. Ver www. reedexpo.com e www.reedalcantara.com.br. Acesso em: 26/01/2016.

${ }^{8}$ FIFA: Fédération Internationale de Football Association. Organização fundada em 1904 para reunir as associações nacionais de futebol e organizar padrões internacionais do

๑ jogo. Especialmente a partir da década de 1970, passa a

- ter uma operação global. Com sede em Zurique, Suíça, a

จ FIFA possui 209 nações associadas (www.fifa.com/associa-

ง tions). COI: Comitê Olímpico Internacional. Organização

Q fundada em $1894 \mathrm{com}$ o intuito de organizar os primeiros

¿ jogos olímpicos modernos, que ocorreram em 1896, em

\& Atenas, Grécia. Com sede em Lausanne, na Suíça, o COI

i opera internacionalmente através dos Comitês Olímpicos

is Nacionais, que hoje estão presentes em 206 países. Ver

เ่ http://www.olympic.org/national-olympic-committees.

+ 9 Algumas empresas de arquitetura são responsáveis por

2 vários dos mais recentes projetos de estádios. A empresa

$\stackrel{\infty}{\curvearrowright}$ Popoulos, com sede nos Estados Unidos, concebeu o está-

\& dio das Dunas, de Natal, para a Copa do Mundo de 2014,

o Estádio Nacional de Sidnei para as Olimpíadas de 2000

i e o estádio de Johannesburg (Soccer City) para a Copa do

$>$ Mundo de 2010. A empresa Herzog \& de Meuron, com

i sede na Suíça, concebeu o estádio Alianz Arena, em Mu-

nique, para a Copa do Mundo de 2006, e o Estádio Nacio-

nal de Pequim (o "ninho de pássaro") para as Olimpíadas

क

Alemanha, projetou três estádios para a Copa do Mundo

I de 2010 (da Cidade do Cabo, de Durban e de Porto Eliza-

J beth) e três estádios para a Copa do Mundo de 2014 (de

\& Manaus, de Brasília e de Belo Horizonte). Várias fontes.

Ver, especialmente, os sites das empresas citadas. Sobre a

construção das novas arenas como novo padrão do espetá-

U. culo esportivo, ver Damo e Oliven (2014). vention Bureaux) e os departamentos estatais de turismo (como a Embratur), que também assumem a função para promover a imagem de lugares (cidades, países) no exterior.

Os grandes eventos são operados, dessa forma, por uma rede de instituições nacionais e globais, privadas e públicas, construídas por agentes voltados para uma agenda global. Nelma Gusmão de Oliveira (2015), com base em Pierre Bourdieu, notou que esses agentes, embora ligados a órgãos específicos, com interesses próprios, formam um campo relativamente autônomo. É por isso que, apesar de as determinações externas (partido no poder, situação econômica, etc.) interferirem na realização dos eventos, eles continuam ocorrendo de modo muito similar em toda situação.

É possível notar, de fato, vários elementos presentes em todos os eventos. Quero destacar aqui um que possui posição de destaque. Refirome à produção simbólica dos lugares. Para sediar um evento, os lugares competem uns com outros e, dessa forma, precisam aparecer aos tomadores de decisão como mais atraentes. Há agentes especializados nessa função: os consultores de marketing. Um exemplo desse tipo de agente é a empresa Vero, com sede na Inglaterra, pertencente ao publicitário Mike Lee, especialista em assessorar "as candidaturas de federações esportivas, cidades e países a sediarem grandes eventos, liderando tomadores de decisões no mundo esportivo, grandes clubes esportivos e marcas". ${ }^{10}$ Essa empresa está por trás das campanhas vitoriosas de Londres e Rio de Janeiro, para sedes das últimas duas Olimpíadas, e da campanha do Qatar, para sede da Copa do Mundo de $2022^{11}$ (Oliveira, 2015, p. 107). Para tanto, esses agentes buscam produzir simbolicamente os lugares e "vendê-los" aos tomadores de decisão.

Esses agentes se confundem com os publicitários dedicados à produção simbólica do lugar como marca. Ao mesmo tempo em que os even-

${ }^{10}$ Disponível em: http://www.verocom.co.uk. Acesso em: 26/01/2016.

${ }^{11}$ De Oliveira chama esses agentes de detentores de capital cultural e traz uma lista dos mais frequentes nas campanhas olímpicas. 
tos se globalizam, também se globaliza uma forma específica de promoção dos lugares, que passa a utilizar os mecanismos típicos do marketing de produtos e que a bibliografia da área chamou de place branding. De fato, a partir do começo dos anos 1990, vemos lugares (países e cidades) passarem a ser promovidos tal qual marcas, em diversos espaços globais (Nicolau Netto, 2014).

A relação entre marketing de lugar ${ }^{12} \mathrm{e}$ eventos esportivos é direta. Em verdade, em torno deles se forma um discurso circular em que um justifica o outro, criando um processo de reprodução de suas ideias. Uma das principais justificativas para se sediar um grande evento é a suposta promoção do lugar no espaço global. Em processo que vem desde os anos 1990, a partir de 2003 a Carta Olímpica introduz a diferença entre os legados olímpicos tangíveis atrair capital global e firmas internacionais (Avraham; Ketter, 2008, p. 13-14).

Dessa forma, não surpreende que os países que recebem os grandes eventos também operem programas de marketing de lugares. Como os grandes eventos, o marketing se torna elemento ritual dos lugares na globalização. Mostrei em outro lugar, como esse tipo de marketing se torna prática comum na contemporaneidade (Nicolau Netto, 2014) e aqui apenas relembro que o Brasil, através da Embratur, desenvolve um programa desse tipo, chamado Plano Aquarela, desde $2005^{14}$ (Molina, 2015, p. 100-138).

Dessa forma, há uma circularidade entre grandes eventos e marketing de lugar, como no Gráfico1. e intangíveis. Nos legados in- Gráfico 1 - 0 discurso circular dos grandes eventos e do marketing de lugar tangíveis, "são invocados os efeitos do city marketing. Estão aí inclusos: a capacidade de criar uma imagem positiva da cidade e do país anfitrião e de aumentar o orgulho cívico dos habitantes ou fortalecer sua identidade; o incremento na indústria do turismo devido à projeção que o evento alcança na mídia [...] (Oliveira, 2015, p. 124)”. ${ }^{13}$

Da mesma forma, os planos de marketing dos lugares são justificados na via inversa, por seu suposto poder de atrair os grandes eventos. Segundo um autor da área, entre outras razões,

Os lugares são marketed e suas imagens são reconstruídas para que possam ter sucesso em rivalidades nacional e internacional para sediar exposições e eventos esportivos tais quais os Jogos Olímpicos e

12 Traduzirei place branding por marketing de lugar por falta de termo melhor, uma vez que, embora ambos sejam anglicismos, marketing é, há tempos, um termo presente em nossos dicionários. Certamente essa tradução desagradaria os publicitários, que insistem, com razão, na diferenca de marketing e branding. Contudo, para os fins deste artigo, a confusã̃o de termos não é prejudicial.

${ }^{13}$ Glauco Roberto Gonçalves (Gonçalves, 2016, p. 64-121) faz uma espécie de compilação de pronunciamentos de representantes estatais brasileiros que justificaram a realização da Copa do Mundo no país em virtude dos benefícios de promoção internacional de sua imagem. 
Esses funcionários e donos de agências de comunicação formam o que Melissa Aronczyk chamou de classe promocional transnacional, definida como um "grupo de atores diversos voltados para a manutenção da legitimidade da forma nacional para uma gama de propósitos de geração de lucro" (Aronczyk, 2013a, p. 9), entre os quais o recebimento de grandes eventos. Eles são os agentes de um campo discursivo que eles mesmos produzem e do qual retiram seus ganhos. Esse campo é mobilizado a produzir simbolicamente um tipo de lugar, cada vez mais o lugar-modelo em um imaginário global. No próximo item deste texto, busco explicitar a base da legitimidade das ideias desse campo. No item seguinte, discuto as condições de produção desse discurso como um "senso comum planetário” (Ortiz, 2006, p. 49-84).

\section{O CAMPO DISCURSIVO DO MARKE- TING DE LUGAR}

Renato Ortiz afirma que "o processo de mundialização da cultura pressupõe a existência de instituições transnacionais que desempenham um papel pedagógico [...]. Elas elaboram uma visão escolástica cuja intenção é validar nossa compreensão das questões e dos problemas por elas julgados relevantes" (Ortiz, 2006, p. 50). Boltanski e Chiapelo (2009, p. 3-132) notam também o trabalho de certas instâncias globais na produção de um discurso empresarial que justifica um "novo espírito do capitalismo". Para esses autores, essa produção "intelectual" está mais nas mãos de pessoas diretamente ligadas a empresas e aos interesses econômicos dominantes do que dos intelectuais propriamente ditos. Sigo na mesma linha desses autores e proponho aqui que os publicitários que atuam transnacionalmente desempenham um papel pedagógico que nos "ensina” a conceber uma cultura relacionada a lugares, criando um "senso comum planetário" daquilo que ainda chamamos de identidade, mas que hoje já confundimos com uma marca. No momento em que o trabalho desses publicitários encontra, nos grandes eventos, uma plataforma mediática global, eles produzem uma nova forma de imaginário, marcado pela globalidade das imagens.

A eficácia simbólica de todo discurso só pode ser compreendida se relacionarmos as propriedades discursivas às "propriedades daquele que o pronuncia e às propriedades da instituição que o autoriza a pronunciá-lo" (Bourdieu, 1996, p. 89). A legitimidade do discurso de um publicitário, ao contrário de toda perspectiva individualista definidora do habitus de classe desses agentes, não se dá pelo ato milagroso de suas palavras, mas por um sistema de agentes e instituições que constroem, ao mesmo tempo, a crença nessas palavras e a vontade de se crer por aqueles que as consomem.

Muitos trabalhos foram feitos para explicar os processos sociais que embasam a transformação do lugar em marca. Uma posição constante se refere às transformações econômicas vividas especialmente a partir da década de 1970, o que torna a mobilidade do capital cada vez maior, sempre à procura do lugar em que poderá retirar seu maior retorno. Ao mesmo tempo em que o lugar se torna, então, elemento central para a valorização do capital, há pouca garantia para a manutenção desse capital em cada lugar. Dessa forma, os governos se esforçam por mostrar os lugares sempre e cada vez mais atraentes a esse capital, adotando um tipo de governança estatal baseada no empreendedorismo, como aponta David Harvey (2001, p. 161-188). ${ }^{15}$ Segundo o autor, um dos interesses dessa governança é a atração daquilo que, derivando de Bourdieu, ele chama de capital simbólico do lugar.

O capital simbólico coletivo vinculado a nomes e lugares como Paris, Atenas, Nova York, Rio de Janeiro, Berlim e Roma é de grande importância, conferindo

\footnotetext{
${ }^{15}$ Em documento de 1998, o Banco mundial apontava que as cidades precisam: Competir pelo investimento de capital, tecnologia e competência gerencial; competir na atração de novas indústrias e negócios; ser competitivas no preco e na qualidade dos serviços; competir na atração de força de trabalho adequadamente qualificada (apud Vainer, 2002, p. 77). Citação lembrada na leitura da tese de Glauco Roberto Gonçalves (Gonçalves, 2016).
} 
a tais lugares grandes vantagens econômicas em relação a, por exemplo, Baltimore, Liverpool, Essen, Lille e Glasgow. O problema para esses lugares citados em segundo lugar é elevar seu quociente de capital simbólico e aumentar seus marcos de distinção, para melhor basear suas alegações relativas à singularidade geradora da renda monopolista (Harvey, 2001, p. 231).

Essa perspectiva é falha ao resumir a competição entre os lugares à esfera econômica. Em verdade, os lugares não competem apenas pela atração de um capital econômico móvel, mas por diversas formas globais de influência: política (como a condição de pertencimento a comissões e comitês internacionais), tecnológica, social, cultural, ${ }^{16}$ etc. Enfim, os lugares competem também por algo que genericamente se pode chamar de prestígio, no sentido de Weber, o que não está à parte, mas não se resume a ganhos econômicos. Contudo, mesmo essas outras formas de competição se dão por discursos informados por uma lógica econômica, de livre mercado, de livre competição. O erro da perspectiva acima é confundir uma forma de operação de um discurso com suas funções. Adota-se um discurso típico de corporações para a competição entre lugares, mas por ganhos que não são apenas econômicos.

Para se compreender esse processo, é necessário investigar os artífices desse discurso relativo às bases da competição global entre os lugares. É evidente que os publicitários não inventam o contexto no qual os lugares competem uns com outros pela atração de capitais. Contudo são eles que propõem as bases dessa competição e os meios para se obter sucesso nela. As bases dessa competição assentam na produção do lugar como marca. É claro que tornar um lugar atraente para o capital pode

${ }^{16} \mathrm{Na}$ Expo Mundial de Milão, onde fiz pesquisa de campo, o tema foi alimentação. As escolhas temáticas dos pavilhões de cada país eram bastante variadas. Alguns países adotaram como tema de exibição o incremento de sua produção agrícola (como Brasil e China); outros se voltaram para o uso da tecnologia na produção de alimentos supostamente mais saudáveis (como França, Alemanha e Rússia); um terceiro grupo, ainda, exibiu a suposta adequação de suas culturas gastronômicas nacionais (como Coréia, Emirados Árabes e Angola) para uma melhor alimentação, etc. O que estava em jogo nẫo era apenas uma competição econômica, mas também por uma dimensão de prestígio. envolver uma série de medidas, muitas das quais estamos bastante habituados: definição de taxa de juros, legislação trabalhista, garantia estatal de retorno de investimento, etc. Contudo, em nenhuma dessas ações, os publicitários podem ter ingerência. $\mathrm{O}$ que eles podem fazer para produzir o lugar atraente é sua produção como imagem e, dessa forma, precisam legitimar a competição entre os lugares como uma competição entre imagens, que constitui a forma eficaz para atrair o capital transnacional. Mais ainda: precisam legitimar a si próprios como os detentores de saberes e técnicas capazes de obter sucesso na competição. É esse processo de legitimação de uma visão (o tipo de competição) e de um saber (as técnicas da competição) que importa investigar aqui.

Trazendo, então, para seu campo a possibilidade de mobilização ideal de um contexto concreto, os publicitários propõem, centralmente, que os lugares podem ser promovidos no mercado internacional nas mesmas bases que os produtos. De fato, para esses agentes, a diferença entre o lugar e o produto é irrelevante; se as técnicas do marketing são as mais aptas para vender produtos, também são as mais aptas para "vender" o lugar ${ }^{17}$ (ver Quadro 1, no anexo).

Os publicitários propõem que a competição global entre lugares se dê centralmente em torno de suas imagens e que essas imagens, para se tornarem mais competitivas, devem ser produzidas a partir das técnicas de marketing que eles próprios oferecem. Os publicitários definem, portanto, as regras da competição e oferecem as técnicas do bom desempenho. Fazem mais: consagram os modos de medição de resultados, lançando influentes rankings que comparam os "valores" das marcas de cada nação e de cada cidade. ${ }^{18}$

A proposta desses agentes parece bastante convincente e cada vez mais se espalha pelo

${ }^{17}$ Nos quadros, eu trago exemplos de discurso de publicitários (quando não é o caso, anoto), no intuito de dar ao leitor um conhecimento direto dessa produção discursiva.

${ }^{18} \mathrm{O}$ mais influente desses rankings foi criado por Simon Anholt, um dos agentes que aparecerá diversas vezes neste texto. Ver: http://www.simonanholt.com/Research/research-introduction.aspx. Acesso em: 19/02/2016. 
mundo. De fato, os publicitários bem sucedidos possuem uma cartela ampla e globalizada de clientes. Simon Anholt, que se autoatribui a criação do termo nation branding em 1996 (Anholt, 2007, p. xi), hoje presta assessoria para Austrália, Nova Zelândia, Chile, Holanda, Ilhas Faroe e Letônia. ${ }^{19}$ A empresa de Wally Olins, Saffron, tem como clientes Timor Leste, Lituânia, Londres, Turquia, Irlanda do Norte, Polônia, Bengala Ocidental e um distrito de Londres, Nine Elms. ${ }^{20}$ A empresa de Josep Chias, Chias Marketing, apenas no Brasil já trabalhou ou trabalha com Curitiba, Rio de Janeiro, Paraíba, Santa Catarina, Pará e São Paulo. ${ }^{21}$

A legitimidade e a globalidade do discurso desses publicitários são espantosas e não podem ser explicadas apenas pelo contexto. É necessário que se compreendam as condições sociais da produção do discurso que esses agentes proferem, ao mesmo tempo em que são reconhecidos como detentores de um saber e de uma verdade mesmo por agentes em campos estranhos aos publicitários. Em verdade, o discurso do marketing do lugar, embora produzido no campo da publicidade, é operado no campo burocrático. Aqui está uma diferença central entre a marca de um produto e de um lugar: se, no primeiro, o receptor do discurso é uma corporação, no segundo, trata-se do Estado (ver Quadro 2, em anexo).

đં esforçam em demonstrar que seus trabalhos são uma forma contemporânea de operação diplomática. Dessa forma, eles precisam se legitimar no campo da diplomacia e não é de se estranhar que uma das principais revistas da área tenha como título Place Branding and $\mathrm{Pu}$ blic Diplomacy. Nos escritos dos publicitários, N a suposta competência de operação no campo

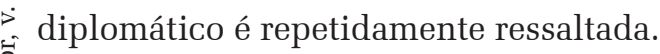

O contexto cria, nos agentes do campo

19 http://www.simonanholt.com/FieldNotes/casenotes-introduction.aspx

${ }^{20}$ http://saffron-consultants.com/sector/places/

${ }^{21}$ Entrevista com representantes na sede empresa em São Paulo (16/07/2013). diplomático, a boa vontade em receber os discursos dos publicitários, pois eles trazem consigo uma noção comercial para a promoção do lugar que está de acordo com os interesses de uma "governança empreendedora". Contudo, ainda assim, são agentes de outro campo, que propõem uma relação entre lugar e produto estranha à diplomacia. De forma complexa, os publicitários precisam, ao mesmo tempo, legitimar uma forma de competição entre os lugares (baseada na imagem), suas técnicas de marketing de lugar e sua própria atuação no campo da diplomacia. Para tanto, eles precisam mobilizar um discurso que justifique o que fazem não como a visão de um grupo particular de agentes, mas como um processo neutro e, especialmente, desinteressado. Em outras palavras, eles precisam mostrar que as técnicas do marketing do lugar não devem ser mobilizadas porque eles têm interesse em seu uso (afinal, é a base de seus negócios), mas porque são técnicas de fato eficientes na promoção internacional do lugar, e o saber que eles têm sobre essas técnicas os legitima. Para isso, os publicitários do marketing do lugar vão se valer do poder da ciência e mobilizar um discurso que se justifica como científico.

Em vários textos que esses agentes produzem lê-se que o marketing do lugar é algo antigo. Contudo as técnicas utilizadas até recentemente não traziam as bases científicas que os publicitários, especialmente a partir da década de 1990, seriam capazes de mobilizar (ver Quadro 3, em anexo).

A proposta de um discurso científico, que embasaria o marketing do lugar, é garantida pela filiação universitária dos publicitários. É marcante como a marcação desse vínculo transpassa seus textos, sendo comum que eles se refiram uns aos outros como professores. Como exemplo, em uma compilação organizada por Nigel Morgan e Annette Pritchard sobre place branding, logo na primeira página do livro, a vinculação acadêmica dos editores é marcada. Ainda, dos 24 colaboradores presentes na compilação, 19 deles se apresentam 
com títulos acadêmicos, entre os quais 13 com títulos de professores universitários.

A universidade, portanto, é a instituição que garante a legitimidade científica do discurso dos publicitários para que eles operem no campo diplomático como supostamente desinteressados na aplicação das técnicas nas quais, de fato, têm interesse. A mobilização desse discurso científico permite ainda outros dois ganhos para os publicitários. Primeiramente, eles podem se propor globais, pois o método científico garantiria a universalidade da aplicação de suas técnicas. Dessa forma, embora busquem a construção da especificidade dos lugares que os diferencie na competição global, os métodos que usam podem ser compartilhados por todos, justificando a presença constante do trabalho de um mesmo publicitário em vários lugares (ver Quadro 4, em anexo).

Os métodos científicos garantiriam ainda a infalibilidade da proposta dos publicitários. Dessa forma, eles são sempre capazes de atribuir o fracasso de uma campanha de marketing de lugar (muito mais comum do que seu sucesso, mesmo nos termos dos publicitários) ao uso equivocado das técnicas, mas nunca aos próprios pressupostos desses usos (ver Quadro 5, em anexo).

O discurso dos publicitários se mantém em pé, pois apresenta uma lógica interna que se baseia em uma suposta homologia entre mercado e mundo, o que permite a confusão entre a imagem de lugares e de produtos. Nesse sentido, como em muitos outros, os publicitários compartilham uma interpretação da globalização com administradores e economistas estudados por Renato Ortiz (2003) em Mundialização e Cultura. Para eles, tanto quanto para os publicitários, os países são unidades de um todo único, sendo esse todo descrito com as mesmas bases com que descrevem uma empresa. Como uma grande corporação multinacional que se espalha por diversas unidades, sendo cada unidade determinada pelo todo, assim é o mundo em relação aos países. Dessa forma, as especificidades nacionais são pensa- das pelos publicitários como variações discretas do todo, que possuem um duplo caráter.

De um lado, as variações são produtivas na medida em que apresentam oportunidades para o oferecimento de produtos e serviços. Michael Porter, professor baseado na escola de negócios de Harvard, ${ }^{22}$ é claro nesse ponto:

Para mim, homogeneização e segmentação não são
incompatíveis. Como menciona Ted Levitt, cada vez
mais ocorre a homogeneização através dos países.
Porém, o que ele não disse é que ocorre também, no
interior desses países, uma segmentação; explorar
em paralelo essas duas tendências é tirar uma van-
tagem global, que até então não existia (Porter, 1990,
apud Ortiz, 2003, p. 171).

A segmentação, palavra que serve no discurso da área para se referir às diferenças locais, significa uma ampliação de mercado para os publicitários, uma vez que esse tipo de serviço só faz sentido se ele pode oferecer a própria especificidade. No caso do marketing de lugar, a especificidade será ofertada a partir do trabalho que se faz em torno da diferença (ver Quadro 6, em anexo).

Ou seja, apenas é possível se ofertar a diferença na medida em que se podem identificar especificidades nos lugares. Em outro texto, já trabalhei com a forma de apresentação da diferença pelo marketing de lugar em relação à identidade nacional e à diversidade (Nicolau Netto, 2014). Aqui, apenas remeto ao fato de que a diferença produzida pelos publicitários só pode ser legítima uma vez que demonstre alguma relação com uma memória coletiva, minimamente reconhecível nacional e internacionalmente. Assim, se os publicitários responsáveis pela marca Brasil selecionam elementos ligados à diversidade étnica, o fazem a partir de uma memória coletiva. Ao mesmo tempo, só se pode ofertar diferença (na forma de branding) a todos os lugares na medida em que eles são entendidos como determinados

${ }^{22}$ Autor de diversos livros sobre administração e trabalhos de consultoria para empresas, Michael Porter passou, na década de 1990, a também publicar livros sobre nação (Porter, 1990) e a prestar servicos para governos nacionais. Assim, é dele a campanha publicitária desenvolvida pela Líbia, ainda sob o regime de Gadaffi (Aronczyk, 2013c, p. 29). 
por um todo, sendo possível, então, uma competição entre imagens gerenciada pelos publicitários, especialistas nessa competição, cujas bases eles próprios criaram.

De outro lado as variações são um obstáculo para os publicitários. Não posso aqui resgatar um debate mais amplo sobre globalização, mas é fácil de se perceber que o mundo não é homólogo ao mercado, tampouco as nações podem ser resumidas a unidades determinadas de um todo, com variações insignificantes. O que importa notar é que essa realidade se apresenta em todo momento, no trabalho que os publicitários desenvolvem, causando o perigo de expor que a homologia entre mercado e mundo é a representação de interesses e não a realidade com a qual trabalham. Dessa forma, a estratégia utilizada por esses agentes para manter o discurso que proferem como crível é buscar afirmar como externo tudo aquilo que não pode ser resumido a uma lógica de mercado proferida por eles mesmos.

Assim é a política. Embora os publicitários do marketing de lugar dependam de governos para contratarem seus serviços e do Estado para legitimar a imagem do lugar que criam embora precisem atuar no campo da diplomacia, eles precisam garantir que esses elementos não contaminem a coerência interna de seu discurso, baseado na homologia entre mercado e mundo. De um lado, os publicitários buscam insistir nas vantagens do mercado, uma insistência que, evidentemente, não é uma exclusividade desses agentes, mas que ganha contornos específicos em suas vozes. De fato, para os publicitários, as vantagens do mercado ultrapassam o aspecto econômico. A afirmação de Anholt a seguir baixo é extrema, mas variações dela constituem a prática desse campo discursivo:

Eu sempre defendi que a visão do mundo baseada no mercado, na qual a teoria da Identidade Competitiva é amplamente predicada, é um modelo inerentemente pacífico e humanístico para as relações entre nações. É baseada em competição, escolha do consumidor e poder do consumidor; e esses conceitos estão intimamente ligados à liberdade e poder do indivíduo. Por essa razão, parece muito mais provável em resultar em duradoura paz mundial do que um estadismo baseado no território, poder econômico, ideologias, políticas ou religião (Anholt, 2007, p. 125).

Na mesma medida que há o elogio do mercado, há a condenação da política. Entre as principais falhas possíveis na execução de um projeto de marketing de lugar, um elemento aparece constantemente na lista negra dos publicitários: "o frequente papel destrutivo da política” (Morgan; Pritchard; Pride, 2004, p. 5).

Os publicitários de marketing de lugar atuam no campo da política, mas operam nesse campo de maneira específica. Eles só podem obter sucesso nesse campo se puderem denegar suas regras, ao invés de a elas aderirem. Isso porque os publicitários são estranhos, recém-chegados àquele campo, destituídos de todos os capitais relevantes para sua operação. Tal denegação só é possível por uma mobilização complexa de capitais adquiridos em outro campo (o campo científico), uma legitimidade emprestada pela ciência e pela formulação de um discurso que propõe a homologia entre mercado e mundo, algo condizente com um contexto social atual.

\section{A GLOBALIDADE DO MARKETING DE LUGAR}

O intérprete que impõe sua interpretação não é apenas alguém que dá a última palavra numa querela filológica (objetivo que equivale a um outro), mas também, com muita frequência, é alguém que dá a última palavra numa luta política, alguém que, apropriando-se da palavra, coloca o senso comum do seu lado (Bourdieu, 2004, p. 137).

A coerência interna de um discurso e sua adequação a um contexto não são suficientes para o sucesso desse discurso. Proponho outros dois elementos determinantes nesse processo, ligados, como é o foco aqui, à condição social de produção do discurso: o interesse 
daqueles que o recebem e sua relação com os megaeventos.

Os publicitários são ambiciosos e desejam que suas visões se espalhem por todas as esferas do Estado (ver Quadro 7, em anexo).

Vimos, acima, que o capital científico que mobilizam é condição para tanto. Contudo, todo discurso efetivo, nos lembra Weber (2006, p. 94) ao pensar sobre os profetas, são discursados para os iniciados. Dessa forma, o discurso do marketing dos lugares é regularmente recebido pelos departamentos de turismo estatais. É evidente que isso se dá porque há uma relação direta entre a promoção turística contemporânea e a competição entre lugares com base na imagem. Diversos autores já demonstraram que, nos últimos anos, a competição entre lugares e países pela atração de turistas se tornou "frenética" (Judd; Fainstein, 1999, p. 2), sendo cada vez mais comum que departamentos de turismo estatais se utilizem das técnicas de marketing como modo de atuação nesse cenário (Holcomb, 1999). Mirian Greenberg (2008) demonstra como a campanha I <coração> NY, lançada em 1977, foi a primeira a promover um lugar a partir da liderança de um departamento de turismo, ao invés, por exemplo, dos departamentos ligados a políticas exteriores.

Dessa forma, pela própria concorrência no meio, os profissionais de turismo cada vez mais se especializam em marketing, quando não são eles próprios formados na área, e utilizam desse conhecimento como forma de distinção entre seus pares. Baseio-me em pesquisas de campo desenvolvidas entre 2013 e 2015 em departamentos de turismo de São Paulo (SPTuris), Rio de Janeiro (RioTur), Mato Grosso (Sedestur) e Brasil (Embratur) e em feiras de turismo (Fitur, Madri; Fit, Buenos Aires; WTM, São Paulo), quando entrevistei representantes de outros departamentos de turismo, não só do Brasil. Essas pesquisas mostraram como o discurso do marketing é determinante para os agentes alocados ali. Sem poder aqui me alongar, lembro apenas que o presidente da Embra- tur a implementar o plano Aquarela de Chias Marketing foi Eduardo Sanovicz, a partir de um primeiro contato com Josep Chias na década de 1990. Sanovicz, então mestrando em turismo (USP), foi à Espanha pesquisar para sua dissertação o projeto de marca desenvolvido por Chias, e seu trabalho final atesta o conhecimento de marketing que adquiriu (Sanovicz, 2001). O antecessor de Sanovicz na Embratur, Caio Carvalho, apresentou sua tese de doutorado na Escola de Comunicação e Artes da USP enquanto presidente da SPTuris (sucedendo, exatamente, Sanovicz). Nela, ele dedica várias páginas à discussão sobre branding e anuncia que "A cidade de São Paulo deve iniciar seu processo de branding nos próximos meses, acompanhando as tendências e as pesquisas realizadas" (Carvalho, 2009, p. 24).

Destaco, portanto, que os agentes de turismo conhecem a bibliografia dos publicitários, sendo comum citarem não apenas seus conceitos, mas também seus nomes, com predileção para Simon Anholt, presença constante nas entrevistas que empreendi. Dessa forma, entende-se que o discurso do marketing de lugar costuma entrar no Estado através dos departamentos de turismo não apenas por uma suposta relação intrínseca e "natural" entre turismo e o discurso dos publicitários, mas por interesses e disputas dos próprios agentes que atuam nesses departamentos.

Contudo a ambição dos publicitários é mais ampla, não se reduz ao turismo. O que eles se propõem a fazer é o estabelecimento de visão sobre a produção simbólica do espaço, reduzida à noção de branding, que embase toda forma de relações internacionais. O modelo que propõem, como se viu na citação de Anholt acima, talvez encontre, na Coreia do Sul, sua realização mais próxima. Naquele país, desde 2009, há um "Conselho Presidencial sobre Nation Branding" (Cheng, 2008), levando o discurso dos publicitários para o espaço mais central do poder estatal.

Embora o caso coreano seja extremo, o trabalho dos publicitários tem implicações em 
todo lugar muito mais amplas do que apenas no setor de turismo. Há uma transformação na própria ideia contemporânea de identidades coletivas (étnicas, nacionais, etc.), algo que Celeste Mira (2014) e Melissa Aronczyk (2013a) também notaram, que cada vez mais passa a ser pensada nos termos de marca. Não vivemos em um mundo em que podemos considerar o discurso dos publicitários como único. As imagens de lugares, as formas de mobilização das identidades, como os movimentos sociais não nos deixam esquecer, estão longe de poder ser resumidas às marcas. Contudo, o discurso dos publicitários encontra hoje condições propícias para se globalizar e produzir uma visão sobre o lugar apropriada a seus interesses.

Arjun Appadurai percebe que a imaginação se torna cada vez mais presente em nosso cotidiano, produzida cada vez mais por fluxos globais (Appadurai, 1996, p. 4-10). Em nosso dia a dia, somos invadidos por imagens que circulam o globo, criando, em nós, um compartilhamento simbólico que se desterritorializa e, dessa forma, não se reduz às fronteiras nacionais. Nosso imaginário, uma vez nacional (Anderson, 1991), se torna global; um imaginário que todos compartilhamos através das fronteiras nacionais, embora de forma desigual. Esse imaginário, contudo, é produzido sob certas condições. O que se argumenta aqui é que o discurso dos publicitários de marketing de lugar produz um senso comum - baseado na homologia entre mercado e mundo - que se torna planetário, na medida em que forma um imaginário global, devido à sua relação com os grandes eventos. Em outras palavras, são especialmente ¿. os grandes eventos, por sua potência mediática $\stackrel{\infty}{\wedge}$ e global, que permitem que o discurso dos puoิ blicitários ultrapasse o setor turístico e se torne $\therefore$ a forma cada vez mais presente e geral como imaginamos os lugares na globalização.

Kang e Taganou (2011) afirmam que os grandes eventos (referem-se especificamente às Olimpíadas) devem ser analisados ao mesmo tempo como espaços de presença física, de interação direta, e espaços mediáticos, em que circulam imagens em lugares muito além daqueles em que o evento concretamente ocorre. Para tanto, eles mobilizam o termo espaço-mídia para se referir aos espaços concretos dos grandes eventos (como o estádio nacional de Pequim), termo pelo qual eles querem afirmar que não apenas ambos os processos estão envolvidos nos grandes eventos, mas um processo atravessa o outro. Assim, tanto as transformações urbanas e o encontro entre pessoas são influenciados pelo espaço mediático (a forma de disposição das pessoas nos estádios; as imagens presentes nos lugares dos eventos, a localização dos estádios, etc., são influenciadas pela imagem que será transmitida ao mundo), quanto as imagens mediáticas são relacionadas à forma como as pessoas concretamente interagem (as imagens das multidões torcendo), à arquitetura dos estádios, etc.

Se, portanto, não é possível reduzir um grande evento a um evento mediático, é preciso reconhecer o caráter mediático desses eventos como uma dimensão cada vez mais central (Roche, 2000, p. 159-193). Especialmente a partir da década de 1990, a preocupação dos agentes dos grandes eventos com sua transmissão televisiva cresce imensamente, algo que pode ser notado em diversas esferas, como já destaquei em outro texto. ${ }^{23}$ Aqui, limito-me a apontar que a produção da imagem dos Jogos Olímpicos e da Copa do Mundo representa praticamente a totalidade dos faturamentos, que crescem de evento em evento, de suas agências (respectivamente COI e FIFA). Dessa forma, a Copa do Mundo de 2014 representou, para a FIFA, um faturamento de 5.1 bilhões de dólares, o que significou 90\% do total entre 2011 e 2014 (FIFA, 2015, p. 17). A maior fatia adveio da venda de direitos para a transmissão de TV, 2.4 bilhões de dólares, mais do que o dobro do que a FIFA arrecadou com os mesmos direitos entre 1999 e 2002 (FIFA, 2003).

O crescimento nos valores de transmis-

${ }^{23}$ Ver "A hierarquização simbólica do Brasil na Copa do Mundo", texto inédito, aprovado na Revista Sociedade e Estado (UnB). 
são se deu na mesma medida em que FIFA e COI passaram a ter maior controle sobre as imagens direta ou indiretamente relacionadas aos eventos. A partir de 1999, todas as imagens durante os jogos passaram a ser geradas por empresas contratadas pelas entidades (HBS - Host Broadcast Services, pela FIFA; OBS - Olympic Broadcasting Services, pelo COI) e, desde então, exatamente as mesmas imagens são assistidas por qualquer espectador, independentemente de onde esteja. As emissoras licenciadas foram impedidas, por contrato, de qualquer interferência na transmissão, não mais podendo decidir o momento de repetição de um lance e, no caso da Copa do Mundo, nem o momento de início e encerramento das transmissões.

O controle sobre a produção e a transmissão da imagem tornou a Copa do Mundo e as Olimpíadas eventos cada vez mais valorizados para a exposição de marcas corporativas. Isso porque as entidades, FIFA e COI, são capazes de oferecer para as corporações a garantia do modo de exibição de suas marcas, a exclusão de marcas concorrentes e a projeção dessas marcas simultaneamente em todo o mundo. Dessa forma, não surpreende que os direitos de marketing pagos pelas empresas parceiras e patrocinadoras da FIFA tenham representado a segunda maior fatia de faturamento da entidade: 1,82 bilhão de dólares em 2014. Direitos de marketing e direitos de transmissão somaram, então, quase $83 \%$ de todo faturamento da entidade em relação à Copa do Mundo de 2014.

Dessa forma, os grandes eventos são, hoje, amplamente determinados pela dimensão mediática de suas imagens, sendo elas produzidas pela lógica comercial, uma vez que buscam vender os produtos que as marcas simbolizam..$^{24}$ A centralidade mediática dos grandes eventos

${ }^{24}$ Lembro, mais uma vez, que dizer que as imagens são produzidas em uma lógica comercial não é dizer que elas são utilizadas apenas para fins comerciais. Justamente aqui está a força do discurso dos publicitários, uma vez que a imagem do lugar que produzem levaria não apenas a aumentar as exportações de um lugar ou sua atração de turistas, mas também seu prestígio no espaço global. De fato, tais impactos não comerciais estão previstos nas propostas dos publicitários e lhes servem de medição do sucesso de seus trabalhos, conforme os critérios formadores dos rankings que produzem sobre as marcas lugares. Ver nota 18. permite que os publicitários encontrem, assim, um ambiente ideal para a propagação de seu discurso de marketing do lugar, de um lado, pois permite a generalização desse discurso. Appadurai (1996), mais uma vez, nota que a mídia é a instância principal na produção de um imaginário global, algo similar ao que argumentam outros autores (Cf. Snerszynski; Urry, 2002), de outro lado, pois as imagens dos lugares ocupam nesse espaço-mídia, de fato, a forma de uma marca. Isso se nota de duas maneiras: pelo uso dos lugares em propagandas de produtos e pela própria disposição das imagens, colocando os lugares lado a lado, em competição, com produtos. No primeiro caso, refiro-me ao uso que os patrocinadores e as entidades organizadoras dos eventos fazem da imagem dos lugares que os sediam em suas propagandas. Pensemos, no caso das últimas edições da Copa do Mundo e das Olimpíadas, o uso que faziam a FIFA e o COI de imagens que se remetiam ao Brasil nas vinhetas de início das transmissões dos jogos. Empresas como KIA, Coca-Cola, Sony, Adidas, etc. também elaboraram propagandas veiculadas no mundo todo com imagens do Brasil.. ${ }^{25}$ No segundo caso, refiro-me ao fato de que as imagens dos lugares são expostas nos grandes eventos como marca (em letreiros com o nome dos lugares, em pôsteres de cidades-sede em cores relacionadas ao lugar, etc.), lado a lado, sem diferenciação com os produtos. Na final da Copa do Mundo, bilhões de pessoas viam, em placas que circundavam o campo de futebol, a estilizada palavra Rio de Janeiro e a expressão Brasil Beyond, ${ }^{26}$ ladeadas por marcas de patrocinadores da FIFA. Em verdade, a imagem do lugar competia com as imagens dos produtos.

${ }^{25}$ Preciso novamente me remeter a artigo inédito em que trato longamente desses casos. Ver nota 23.

${ }^{26}$ Essa expressão se referia a uma campanha da APEX-Brasil, a agência ligada ao Ministério do Desenvolvimento, Indústria e Comércio, responsável pela promoção de exportações e investimento. Essa agência tornou-se patrocinadora da Copa do Mundo sob a categoria parceiro nacional. Com isso, pôde exibir sua marca nas placas de publicidade que circundavam os campos dos jogos. A marca que a agência escolheu exibir foi a de uma campanha de nome Brasil Beyond, que visava a promover, no exterior, uma imagem do Brasil. Importante lembrar que a categoria de parceiro indica o tempo de exposição de cada marca, sendo aquela da APEX-Brasil a de menor exibição. 
Dessa forma, no cenário dos grandes eventos a homologia entre mundo e mercado, pregada pelos publicitários e na qual se embasa a legitimidade do discurso que propagam, encontra sua materialidade. Os grandes eventos constroem espaços-mídias que tendem a reduzir o mundo ao mercado, tratando todos os aspectos irredutíveis como externos, como ruídos em uma sinfonia. A globalidade desse cenário também globaliza o discurso dos publicitários sobre marketing de lugares, ao mesmo tempo em que os consagra além dos iniciados agentes de turismo. Quando se fala da promoção internacional do lugar através dos grandes eventos, deve-se pensar, em verdade, na legitimação de um senso comum planetário.

Recebido para publicação em 22 de março de 2016 Aceito em 05 de setembro de 2016

\section{REFERÊNCIA}

ANDERSON, B. Imagined communities: reflections on the origin and spread of nationalism. London, New York: Verson, 1991.

ANHOLT, S. Competitive identity: the new brand management for nations, cities and regions. New York: Palgrave Macmillan, 2007.

. From nation branding to competitive identity: the role of brand management as a component of national policy. In: DINNIE, K. Nation branding: concepts, issues, practice. Amsterdam: Elsevier, 2008.

$\stackrel{0}{\circ}$

Nation-brands and the value of provenance. In: MORGAN, N.; A. PRITCHARD, A.; PRIDE, R. Destinantion i branding: creating the unique destination proposition.

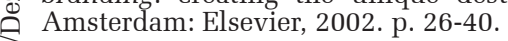

क APPADURAI, A. Modernity at large. Minneapolis: i University of Minnesota, 1996.

If ARONCZYK, M. Branding the nation: the global business เे of national identity. New York: Oxford University Press, + 2013a.

$\dot{2}$

$\infty$. Nation and brand: keywords for the twenty-first

$\stackrel{\infty}{\wedge}$ Century. In: . Branding the nation: the global business

$\dot{a}$ of national identity. New York: Oxford University Press, के 2013b.

$\dot{>}$. Trading Places. In:_. Branding the nation: the global business of national identity. New York: Oxford University Press, 2013c.

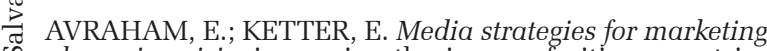
is places in crisis: improving the image of cities, countries

BOLTANSKI, L.; CHIAPELLO, È. O novo espírito do capitalismo. São Paulo: Martins Fontes, 2009.

BOURDIEU, P. A economia das trocas linguísticas. São Paulo: Edusp, 1996.
Leitura, leitores, letrados, literatura. In: Coisas ditas. São Paulo: Brasiliense, 2004.

BUSA, F. Mega-events as catalysts for urban transformation. In: UNITED NATIONS. BUREAU INTERNATIONAL DES EXPOSITIONS.SHANGHAI 2010 WORLD EXPOSITION EXECUTIVE COMMITTEE. Shanghai manual: a guide for sustainable urban development of the 21st Century. 2010.

CARVALHO, C. L. Políticas públicas no turismo brasileiro: a cidade de São Paulo e a construção de sua identidade turística. 2003. 253 f. Tese (Doutorado em Ciências da Comunicação) - Programa de Pós-Graduação na Escola de Comunicações e Artes, Universidade de São Paulo, São Paulo, 2009

CHENG, L. C. The korea brand: the cultural dimension of south korea's branding project in 2008. In:_. US-Korea institute at sais.[S.l;s.n], 2008. Disponível $\overline{\mathrm{em}}$ : <www. uskoreainstitute.org >. Acesso em: 28 Ago. 2015.

DAMO, A.; OLIVEN, R. Megaeventos esportivos no Brasil: um olhar antropológico. Campinas: Armazem do Ipê, 2014.

DINNIE, K. Nation branding: concepts, issues, practice. Amsterdam: BH, 2008.

ELFVING-HWANG, J. South korean cultural diplomacy and brokering k-culture outside Asia. Korean Histories, [S.l], v. 1, n. 4, 2013

FIFA. FIFA Financial Report 2002. Zurich, 2003.

FIFA. FIFA Financial Report 2014. Zurich, 2015.

GONÇALVES, C. A produção espetacular do espaço: as cidades como cenário na copa do mundo de 2014. 2016. Tese (Doutorado em Geografia Humana) - Programa de Pós-Graduação em Geografia Humana da Universidade de São Paulo, São Paulo, 2016.

GREENBERG, M. Branding New York: how a city in crisis was sold to the world. New York: Routledge, 2008.

HARVEY, D. A produção capitalista do espaço. São Paulo: Annablume, 2001.

HOLCOMB, B. Marketing Cities for Tourism. In: JUDD, D. R.; FAINSTEIN, S. S. The tourist city. New Haven: University Press, 1999.

HORNE, J. A construção dos BRICs por meio da construção de estádios: reflexões preliminares sobre os recentes e futuros megaeventos esportivos em quatro economias emegentes. In: SÁNCHEZ, F. et al. A Copa do mundo e as cidades: políticas, projetos e resistências. Niterói: Editora da UFF, 2014. p. 35-44.

KANG, J.; TRAGNOU, J. The beijing national stadium as media-space. Design and Culture, New York, v. 2, n. 3, p. 145-163, 2011.

JUDD, D. R.; FAINSTEIN, S. S. The tourist city. London: Yale University Press, 1999.

KOTLER, P. Foreword. In: MOILANEN, T.; RAINISTO, S. How to brand nations, cities and destinations: a planning book for place branding. New York: Palgrave Macmillan, 2009. p. viii-ix.

MACALOON, J. The theory of spectacle: reviewing olympic ethnography. In: A. TOMLINSON, A.; YOUNG, C. National identity and global sports events: culture, politics and spectacle in the olympics and the football world cup. Albany: State of University of New York, 2006.

MIRA, C. Brasil: da identidade à marca. Ciências Sociais Unisinos, Rio Grande do Sul, v, 1, n. 50, p. 3-13, 2014.

MOILANEN, T.; RAINISTO, S. How to brand nations, cities and destinations: planning book for place branding. New York: Palgrave, 2009.

MOLINA, F. Megaeventos e produção do espaço urbano. São Paulo: Annablume, 2015. 
MORGAN, N.; PRITCHARD, A.; PRIDE, R. Destination branding: creating the unique destination proposition. Amsterdam: Elsevier, 2004.

NICOLAU NETTO, M. Os sentidos da diversidade e da modernidade nas campanhas promocionais contemporâneas da Embratur. In: CASTRO, M. B.; SANTOS, M. S. Diálogos interdisciplinares: literatura e políticas culturais. Rio de Janeiro: Eduerj, 2014. p. 1-26.

OLINS, W. Nation-brands and the value of provenance. In: MORGAN, N.; A. PRITCHARD, A.; PRIDE, R. Destination branding: creating the unique destination proposition. Amsterdam: Elsevier, 2002. p. 17-25.

OLIVEIRA, N. G. O poder dos jogos e os jogos de poder: interesses em campo na produção da cidade para o espetáculo esportivo. Rio de Janeiro: Editora UFRJ, 2015.

ORTIZ, R. Mundialização e cultura. São Paulo: Ed. Brasiliense, 2003.

Mundialização: saberes e crenças. São Paulo: $\overline{B r a s i l i e n s e, ~} 2006$.

PORTER, M. The Competitive Advantages of Nations. New York: Free Press, 1990.
ROCHE, M. Mega-events and modernity: olympics and expos in the growth of global culture. London;New York: Routledge, 2000.

SANOVICZ, E. Proxima estación plaça Calalunya. 2001. Dissertação (Mestrado em Turismo) - Departamento de Publicidade, Relacões Públicas e Turismo da Escola de Comunicações e Artes, Universidade de São Paulo, São Paulo, 2001

SASSEN, S. A Sociology of globalization. New York; London: W. W. Norton \& Company, 2007.

SNERSZYNSKI, B.; URRY, J. Cultures of cosmopolitanism. Soc. Rev., [S.1], 2002.

VAINER, C. B. Pátria, empresa e mercadoria: notas sobre a estratégia discursiva do planejamento estratégico único. In: ARANTES, O. et al. A cidade do pensamento do pensamento único: desmanchando consensos. Petrópolis: Editora Vozes, 2002. p. 75-104.

WEBER, M. Sociologia das religiões e considerações intermediárias. Lisboa: Relógio d’Água, 2006. 


\section{ANEXO}

\section{Quadro 1}

Simon Anholt: "The idea that countries behave rather like brands is by now fairly familiar to most marketers, and to many economists and politicians too" (2002, p. 28).

Philip Kotler: "Marketing is a universal process that can be applied to developing and promoting many entities, including products, services, experiences, places, properties, ideas, causes, and information" (2009, p. viii).

Waly Olins: "I am not suggesting that branding the nation is the same as branding a company, only that many of the techniques are similar; that people are people whether they work in a company or live in a nation and that means that they can be motivated and inspired and manipulated in the same way, using the same techniques" (2002, p. 24).

\section{Quadro 2}

Moilanen e Rainisto: The influence of a place-brand: (...) promotes public diplomacy (2009, p. 1)

Elfving-Hwang: The Lee Myung-bak administration [na Coreia do Sul] (2008-2013) took this initiative further by developing a notion of cultural diplomacy as a form of soft power to strengthen its international and domestic legitimacy, and identified 'nation-branding' as a tool to achieve this image (2013, p. 13).

Melissa Aronczyk (professora de comunicação e sociologia): Nation branding can be provisionally defined as the result of the interpenetration of commercial and public sector interests to communicate national priorities among domestic and international populations for a variety of interrelated purposes. At one level, it is a conscious strategy of capital (re)generation, combining public and private sector resources to generate fiscal advantage. As such, its aim is to help the nation-state successfully compete for international capital in areas such as tourism, foreign direct investment, import-export trade, higher education, and skilled labor. A second dimension of the practice is to convey an image of legitimacy and authority in diplomatic arenas, to earn state leaders and other national elites institutions or organizations (2013b, p. 2).

Documento publicado em razão da Expo Mundial, ocorrida em Shanghai, 2010: Because mega-events carry content and enjoy international backing, they amplify the impact of any branding campaign and help move well beyond standard advertising practices. In addition to showcasing local and national culture, society, and economy to the world they can help the host city take a leading role in catalyzing global attention on a key issue for humanity. Thus, through a mega-event, the city can enrich a branding campaign with content that is meaningful globally and goes beyond traditional commercial techniques. In other words, mega-events tie together city branding and public diplomacy. (Busa, 2010, p. 11)

Philip Kotler: In the case of marketing places, such as nations, regions, cities, and towns, much informal marketing has gone on for centuries. London, Venice, Rome, and dozens of other great cities were known around the world both because of the accounts of travelers as well as the effort of these great cities to attract tourists, skilled workers, investors, and buyers of their products and services. The beginnings of formal marketing planning is a more recent phenomena. In 1993, Professors Irving Rein, Donald Haider and I published Marketing Places, perhaps the first book to open the subject and apply the formal tools of marketing. Over time, we worked with other experts to bring out such editions as Marketing European Places, Marketing Asian Places, and Marketing Latin American Places (2009, p. viii).

Moilanen e Rainisto: "The aim of the present study is to compile a thorough scientific theoretical framework and suggested procedures, based on practical experience, of how to build a brand for a place; country, city or a tourism destination. In the authors' opinion, this planning book and the proposed action plan form a unique entity (2009, p. 1).

\section{Quadro 4}

Avraham: Despite the complexity of devising 'ready-made recipes', here we list a set of guidelines for choosing the most appropriate response strategy. Based on the dozens of case studies in this book, and many others, we have been able to deduce a set of links between CAP [crisis, audience, place] characteristics and choice of SAM [source, audience, message] strategy. Properly integrated in the model, these guidelines can serve every place marketer or place leader in making a quick and easy choice of an effective response strategy (p. 191). 
Quadro 5

Avraham e Ketter: Other factors too have indirectly affected Israel's status in the international tourism arena: high costs of flights and tourism services, the country's location far from other (major) tourist destinations and the lack of medium-level accommodations. In other words, the Israeli case is also a clear reminder that there are other factors affecting the image recovery besides those related to the media. In such cases, it is important to take these factors into account when choosing a response strategy (2008, p. 200).

Moilanen e Rainisto: If the country branding is executed only by politicians, experiences from Eastern Europe show that this approach more often fails than succeeds. A team of respected persons (e.g., branding committee) is needed to persuade politicians, citizens and companies of the long-term benefits of the activities (2009, p. 75).

Moilanen e Rainisto: What Went Wrong in Norway? During the process it became clear for the parties involved that to be able to function country branding could not be separated from the tourism industry, but it required all actors with national visibility to participate. This view is underlined by the following story; at the same time as Norway's tourism industry highlighted Norway as a nice summer destination and beautiful trekking location with amazing fiord scenarios, in the primary market area of Germany, another important industry for Norway, the fishing industry, campaigned with heavy resources on the same markets, where they emphasized that it is always cold in Norway. From the fishing industry's point of view, coldness is a competitive advantage because it is related to freshness of fish. The fishing industry's visual campaigns were based on images of brave fishermen fishing in cold conditions amidst slush and breakers, trying to bring fresh fish to German tables. The two projects were conducted at the same time and were basically pulling on the same strings, just in two different directions. A German consumer does not care who has paid for which campaign. The fact is that in the end, the campaigns gave a vague picture of Norway's weather conditions (Moilanen; Rainisto, 2009, p. 36).

\section{Quadro 6}

Keith Dinnie: A further incentive for countries to embrace branding lies in the capacity of branding techniques to create meaningful differentiation. (...). In the tourism sector, for instance, most destinations make almost identical claims regarding the beauty of their scenery, the purity of their beaches, the hospitable nature of the locals and so on, and therefore, the need for destinations to create a unique identity, to find a niche and differentiate themselves from their competitors, is more critical than ever (2008, p. 695-697).

\section{Quadro 7}

Simon Anholt: Brand management should be treated as a component of national policy, never as a 'campaign' that is separate from planning, governance or economic development. This is why my work now involves building and training teams consisting of head of state or government, cabinet ministers and CEOs of key corporations, in the principles of competitive identity, and coaching them through the process of strategy development and implementation (Anholt, 2008, p. 764). 


\section{THE DISCOURSE OF PLACE AND BIG EVENT MARKETING}

\author{
Michel Nicolau Netto
}

The big events are globalizing in the same way that places promoted as brands are spreading. Although autonomous, these processes are related by being founded in a vision that the places have to compete in the globalization and that the competition must occur based on their images. This type of competition bases itself in a discourse produced by place marketing professionals that manage built symbolic forms as well as engage in the production of new elements in order to configure them, such as products' brands, as a competitive differential. In this article, the action of these marketing professionals is investigated, and they are comprehended as artificers of a "world common sense" that resignifies the image of the place from the conception of a brand. The assumptions of this discourse will be analyzed as well as the legitimacy instances and its relation with big events that may be understood as spaces of consecration and circulation of the place marketing discourse.

Keywords: Globalization. Identity. Marketing. Mots-clés: Mondialisation. Identité. Marketing. Branding. Mega events.

\section{LE DISCOURS DU MARKETING DE LIEU ET LES GRANDS ÉVENEMENTS}

\author{
Michel Nicolau Netto
}

Les grands événements se mondialisent au fur et à mesure que prolifèrent les lieux promus en tant que marques. Même s'ils sont autonomes, ces processus sont en accord avec l'idée d'être fondés dans une optique où les lieux doivent entrer en compétition dans la mondialisation et que cette concurrence commence avec leurs images. Ce genre de compétition part d'un discours produit par les agents publicitaires du marketing des lieux qui manipulent autant les formes symboliques construites comme des identités collectives que leur engagement dans la production de nouveaux éléments afin de leur donner une configuration, exactement comme les marques de produits, qui leur attribue un avantage concurrentiel. Dans cet article, nous étudions les actions de ces agents publicitaires, considérés comme les promoteurs d'un "bon sens planétaire" qui recadre l'image du lieu en partant de la conception d'une marque. Nous $\mathrm{y}$ analysons les hypothèses de ce discours, leurs instances de légitimité et leur lien avec les grands événements, qui devraient être compris comme des espaces de consécration et de circulation du discours sur le marketing des lieux.

Image de marque (branding). Méga-événements. ILAS/Columbia University, em Nova Iorque. Professor do Departamento Sociologia do IFCH/Unicamp e coordenador do Programa de Pós-Graduação do mesmo Departamento. Membro do Grupo de Estudos de Práticas Culturais Contemporâneas - GEPRACC, PUC-SP, e líder do Grupo de Estudos em Pierre Bourdieu - GEBU, Unicamp. Publicações recentes: Música brasileira e identidade nacional na mundialização (2009); O discurso da diversidade e a world music (2014). 